\title{
Evolution and co-evolution of individuals and groups in environment
}

\author{
Juliette Rouchier, Olivier Barreteau, François Bousquet \\ Cirad-Green, Campus de Baillarguet \\ BP 5035, 34032 Montpellier Cedex 1, France \\ \{rouchier, barreteau, bousquet\}@cirad.fr \\ Hubert Proton \\ Laboratoire Systèmes Coopératifs, Ecole des Mines de Saint-Etienne, \\ 158 cours Fauriel, 42023 StEtienne, France \\ proton@emse.fr
}

\begin{abstract}
To study the social organisation of sets of agents managing common property goods, we use multi-agent simulations. This paper describes how the idea of group is analysed in this context. On the one hand agents build constantly themselves and the community, through their actions on their common environment and their different interactions with others. On the other hand the group preexists to the agents and compels their actions. To move beyond this dualism we explore different ways to take in account both organisation levels at a same time. Two approaches of that idea have been implemented and are presented here. The first, modelling the potlatch, deals with emerging collective structures that are observed by the model user and by the agents themselves. The second, simulating irrigated systems, defines both organisation levels as autonomous agents that coevolve in their environment. A tool was specially created to stick together these two approaches and is described in the discussion.
\end{abstract}

The simulation of societies of agents is used in cognitive sciences to implement distributed problems, and in social sciences to represent the world. Being used as metaphors, the modelization of those societies raises questions that are common to both disciplines : between autonomy, control and social norms, what are the role of individuals within the group and the relations between them ?

In the research we lead about common property resources, it is the co-ordination between actors about appropriation and uses of these resources that we consider. Each actor, individual or group, acts on the environment and communicate with the others about these actions. We chose MAS as a tool of representation and experiment to analyse these interactions.

To explain this choice, we will first examine the different ways of handling the existence of several levels of organisation in societies and conclude on Giddens' structuring theory [15]. Then, following on from connectionism in the cognitive sciences [31] and from Habermas' "Theory of communicative action" [20] in the social sciences [26], we assume that human phenomena should be analysed in terms of actions and interactions, both from individual and collective points of view.

To illustrate two ways of considering the collective as built out of individuals, we will then describe two approaches of societies that have been implemented, showing the creation of a collective or describing societies with predefined rules. We will conclude with a tool, created to help to take superposition of organisations and points of view into account.

\section{From individual to collective}

\subsection{Society and the place of the individual}

In social sciences there are different ways of considering human groups and the different levels of organisation that coexist in societies. It is not possible to restrict the observation to local individual actions, because some entities do exist that predate the individuals, have their own dynamics and provide frameworks serving as a basis for human action. But at the same time the society expresses itself only through the actions of its members. It is thus the aim of social sciences to question the relations between the macrosocial phenomena and the implications of the society mem- 
bers [19].

\subsubsection{A society built from individuals}

One way of interpreting these phenomena is to adopt the point of view of methodological individualism. As the individual is the sole component of society, all understanding is based on him: it is thanks to the actions of all members of the group, determined by preferences, that a balance is created, thus giving rise to macro-social phenomena. This analysis is based on a somewhat tautological presupposition: it defines individuals as having intrinsic interests and preferences which are independent of contexts or which can be explained by social meta-preferences [6]. The other base which limits the explanatory value of this approach is the idea of this balance, which is obtained ideally via the cumulative actions of individuals and which has a somewhat magical quality [21].

Another vision of society as built from a set of individuals is developed in interactionism. It differs radically from that of methodological individualism in that it avoids postulating any pre-established meaning or preferences for the individual. It is by interaction with the others and with his environment that the individual, who is constantly evolving, defines his action, the purpose and form of which are never fixed. This adjustment to others no longer produces "a balance of actions but of meaning" [29].

\subsubsection{The macro-social point of view}

The other approach to society tends to remove the global entities entirely from a human context and to find explanations for dynamics and tendencies at this level. We thus observe that these entities develop according to fairly general mechanisms, such as a tendency to reproduce themselves [17]. This highly abstract analysis can be used to grasp a large number of phenomena, but is problematic in that it does not provide answers to the immediate and intuitive questions about the group, such as, for example : where does the sense of belonging to a community come from ? [6].

Because the society needs a material support to express its rules, their existence is manifested through the individuals' actions. That is why rules are not simply constraining and orienting actions (which is the point of view of Dupuy's complex individualism [22]), they also provokes them, and their reproduction partly constitutes their purpose. Thus each action helps to maintain the social fabric and the conditions of its own existence: "through action, the agents reproduce the structuring properties of the society" [15]. While not ignoring the specificity of the macro-social scale, this analysis reaffirms the idea that society is made of independent and creative agents interqcting.

\subsubsection{Moving beyond this dualism}

Several currents of thought in the social sciences and in the field of multi-agent systems have identified this dualism and sought to move beyond it. Ethnomethodology sees man as a permanent sociologist in his own group [8] who makes theories about the frameworks of his action. Interpenetration between the two levels of organization, global and local, is reaffirmed by the meaning arising from the identification of structures by the actors.

However, in order to establish explanatory generalization, we must detect the unconscious structures which, by their very nature, do not appear directly in the discourse of players and must be identified [28]. We see therefore that two ways of apprehending the world must be taken into account simultaneously, the one of social actors and the one of an outside observer [25].

What we can conclude of this brief sum up is that the complexity of human society is of different natures. There is first a multiplicity of autonomous entities (at different scales : individuals or groups), with their own dynamics and rules, that coexist and which influence and command eachother actions. Then the importance of the perception that each of this entities has of the others is crucial in its decision-making, but not enough to understand the global dynamics, for which an external point of view is also needed.

It seems to us that MAS might be a way to express that complexity, in the ability to model several scales for the agents and have them interact, and to build internal and external points of view of the system. For the moment, the question of the apparition of the group is solved by two main means : either there is pre-existence of groups as entities distinct from the agents which constitute them, capable of evolving in response to the behavior of their members [16], or the methods use shared plans which can be attributes of the environment or even complete social agents [35].

The help that MAS could bring to this conception is to help us see the interactions between the entities, their coevolution, as the very base of the society.

\subsection{Me and the others, what interactions?}

The reason why we decide to use multi-agents system to help the understanding of human social groups is because we see actions and interactions as the main point to understand human sociability, more than individual characters, and that an agent in MAS is mainly defined as autonomous and active. 


\subsubsection{Interactions via the environment}

An individual in the world, be it human or animal, gets only two types of minimal information: inside feeling and stimuli. It knows the reaction of its environment to the actions it knows he has performed. By doing correlations, it learns about its influence on the world around and thus buidls its representation of its environment along the time, through repeated experiences [36] [37]. In the world of multi-agent systems, agents act upon their environment according to their perceptions of it [14]. For the domain that use cognitive agents, it is also assumed that these representations are, in turn, transformed by modifications induced in the environment [13][27]: their internal knowledge is based on past actions.

All actions by individuals are thus materialized in an environment. Since it is common to all of them, each individual finds out what the others are doing via the traces that they leave, intentionally or otherwise, in this environment. Hence, because it is shared, the environment is necessarily a place of interaction and as the Palo Alto school expresses it : "it is impossible to not communicate" [38]. This mode of interaction or communication via the environment is used in many multi-agent systems: simulation of ant societies [10], of robot societies [14] or of Paleolithic human societies organized around resources [9]. The shared environment leads us to consider a level of organization different from that of the individual, i.e., the community of individuals acting on this environment and thereby in interaction. The image of society is similarly built up via a circular "active process of reconnaissance and appropriation of situations" [39], based on repeated and compulsory interactions.

\subsubsection{Direct interactions}

These interactions do not necessarily take place via the environment, and may also take the form of aware communication. In that case, the individual acts directly upon the other, and it can take several forms, that we usually all consider as exchanges. The exchanges of messages, using a symbolic language, is a basic form of direct interactions. Another one can be the exchange of goods, which has not only an economic interest but can have an implicit meaning $^{1}$. For example, a gift, by establishing an asymmetrical relationship, creates a binding obligation on the part of the receiver: he must repay the gift [30]. His debt forces him to maintain his link with the other and by accomplishing this act he imposes the same duty upon his interlocutor.

Research in distributed artificial intelligence uses this

\footnotetext{
1 "'Every exchange event is a communication from one person to another of both an artifact (item exchanged) and a social message. The movement of artifact makes exchange important economically. The participant's interpretation of social messages makes exchange important symbolically" [23].
}

metaphor for co-ordination between agents and the various communication protocols constitute one of its main areas of investigation [32]. These protocols correspond to a choice made by the modeller, they must be known and understood by all agents communicating in this way, thus creating levels of organisation other than that of the individual.

Of course, to be an efficient way of communicating, a group must already exist, including all the implied actors, who share a common understanding of the actions. We call mediating objects the tool the people use for this communication [5]. Language (Maturana, 1996) and the notion of exchange [18] are particular cases of such objects which federate these interactions and make them possible. Actually, before any joint action, humans must first agree on a representation of the common world, placing themselves in the same setting [4] and then reaching agreement via repeated communication. A model can also constitute this mediating object as the representation of the world common to various parties [5].

We saw that the gift, by creating a debt, establishes a momentary link. Then, the duty of reciprocity that it brings with, constitutes a social bonding mechanism which guarantees that these links are maintained over time [7]. The forced interactions implied are thus repeated and lead to an agreement on a new mutual understanding [29] about the signification of the action: this is the emergence of new supra-individual organisations.

\subsubsection{In instituted collective frameworks}

Both the environment and the mediating objects are collective frameworks required for the interactions to take place. Other more formalised frameworks may emerge from interactions between individuals as a result of repeated negotiations. They stabilise in the form of social objects which exist in their own right and which, no longer needing to be discussed, become the framework of interactions. Thus the agreements with which economic agents co-ordinate, [12] or institutions, in the sense of "a set of rules in use" [33] are recognised places of interaction which permit co-ordination between players.

The emergence of these collective frameworks is found in multi-agent systems. Co-operative behaviours appear spontaneously in groups, depending on the size and structure of these groups [16]. Collective frameworks are not necessarily sub-groups of the set of individuals of the society in question: the environment and sets of rules also constitute collective frameworks. Shared knowledge may also constitute such frameworks by guaranteeing the content of the communication between one agent and another. Indeed, this is one of the means used to find winning strategies in the game of the prisoner's dilemma [24].

We go back to the conclusion we had: many types of 
supra-individual organisation levels thus exist and define most of the behaviours of the individuals by the means of rules, that are partly identified by the agents themselves. Through the examples of implemented societies, we will then study some interactions between different organisation levels and points of view.

\section{Simulations}

In practice, the purpose of our work is to study the social organization of sets of agents managing common property. Common property management is often seen from the angle of what economists call externalities. Each human perceives his environment, acts upon it and thereby transforms it. The others are then confronted with a new environment. To study environmental problems in more detail and understand the relations between humans and things we must thus focus on the relations between humans about things as well.

As seen in section 1 these interactions are influenced by the norms that take place in the society and the relations between the individual and the collective structures he belongs to. Two multi-agent systems will briefly be described, each experiment treating the question of the existence of collective. The first focuses on social hierarchies and the point of view from which they are observed. The second example shows how the viability of common property management can be seen as a coevolution of two different levels of organization.

\subsection{The potlatch or the construction of a hierarchy}

Here, the subject of human interactions in a society was first viewed from the angle of a system of non-market exchanges, involving more than the simple circulation of goods [18]. To judge the structuring power of this system for society, simulations were performed using multi-agent systems. A description of the potlatch by Franz Boas [3] was used to provide the dynamics of interactions in the implemented artificial world. The constructed universe comprises a resource and 100 agents who act upon the environment through work and upon others via material gifts. Each agent has possessions and slaves who work for him. He acts according to fixed protocols, by offering either gifts or counter-gifts with a value double that of the gift received, the priority being to repay the debt incurred. At each turn, the agent does or does not buy slaves, draws up a plan of envisaged counter-gifts and gifts and offers them.

Each interaction that take place is then stocked in the memory. The agent has no initial knowledge of the others, it can just communicate with them and learn who they are by the way they answer to it. Its memory is thus built at each turn, and there exists criterias that help him judge of the other agents that it met. Then, for the choice of gifts, three behaviours are possible: random, by reciprocity or according to his assessment of others. Several series of simulations have been performed on the basis of each of these three behaviour patterns.

For observation, two points of view co-exist: the one of an external observer on the structure and the one of the agents on the hierarchy they perceive. What makes sense for the agents of the world remains limited to a local point of view. They judge their relations solely on the basis of individual interactions (the duration of their debts) and it is via the superposition of these local views that they understand society as a whole. For the outside observer, it is the place of the individual defined by his links within the group, and his debts, seen as social bonding agents, which is important. Hence are observed, at each time step, the number of meetings during ten turns (sign of social integration), possessions, the number of debtors and debts, the number of slaves.

Different structures appear during simulations, being simply a result of the iteration of exchanges and thus depending on the behaviour chosen. As we saw the overall observation is based on the social integration (the number of regular relations) and the society can show varying degrees of homogeneity in reference to this criterion. It is interesting to compare this judgement with the way it sees its own position in the group. As a general rule, major disparities are revealed: dependency is not experienced in the same way depending upon the level at which it is observed.

These observations shed light on the question of how society should be observed and on the need to superimpose various modes of analysis for a single object. Of course, we do not want the agents to be omniscient, and it is this construction of world views via local actions which we see as interesting. However, analysis on several levels, producing contradictory conclusions, illustrates the risk that agents will construct their actions on the basis of distorted representations of their society if we do not provide them with the option of taking several levels of observation simultaneously into account.

\subsection{Irrigated systems or the coevolution of organi- zation levels}

On the basis of real cases in the middle Senegal River valley, we built a multi-agent system, called SHADOC ${ }^{2}$ to study the viability of a virtual irrigated system [1]. The example of irrigated systems provides a good illustration of the problem examined in this paper: firstly, the water and common infrastructures giving rise to the existence of externalities between farmers constitute a shared resource, and secondly, the farmers belong to a variety of groups and or-

\footnotetext{
${ }^{2}$ Simulateur Hydro-Agricole Décrivant les modes d'Organisation et de Coordination
} 
ganizations set up to grant loans, to manage common infrastructures or to share out water resources. These structures internal to irrigated systems are not the only forms of association existing on a local level. Other external associations also affect the dynamics of irrigated systems. A preliminary version of the model produced simulations which revealed that the social networks to which the farmers belong are more important for the viability of the system represented than the collective water attribution rule [5].

SHADOC was designed with this in mind. It comprises an Agent class inherited by a Farmer class and a Group class. Groups are thus defined as distinct entities, not just as a set of farmers. The Farmer and Group classes have several common attributes at the Agent super-class level. These attributes notably concern economic aspects (kitty, ongoing loans and credits), mail management (in and out mailbox), a list of rules corresponding to what the agent is able to do and a criterion of satisfaction. This satisfaction is calculated with respect to the progress of a cropping season, a representation of the agents with whom the agent is related, especially what it believes that the others can do. In particular, each farmer makes a representation of the rules implemented by the groups to which it belongs and acts accordingly. In principle, the two organization levels formed by these two classes are autonomous. Collective actions are not an emergence of individual behaviors: they depend on the consequences of individual agents' actions and of other groups'. Similarly, individuals are influenced by collective actions as much as the actions of the other Farmer instances. They are not under the exclusive control of a collective framework.

Among the rules available to each Agent instance, there is one called \#assessment, associated with the criterion attribute, that has a special role. It is a meta-rule regulating the evolution of rules from a cropping season to the following one. At the end of each season, the indicator corresponding to the criterion attribute is evaluated locally by each agent and compared with its associated threshold. If the agent is satisfied, it keeps the same set of rules for the next season. If not, it inquires about the results obtained by the other agents of its network, regarding this indicator. For a group, this network comprises the other groups with the same objective (water attribution, access to credit or pumping management). For a farmer, it comprises the farmers belonging to the same social affinity network, restricted in some cases to those belonging to the same groups within the perimeter $^{3}$.

Depending on how his \#assessment rule operates, the agent will either keep his set of rules even if unsatisfactory, or adopt the rules of another agent, among those in-

\footnotetext{
${ }^{3}$ Each farmer instance is in fact a member of three Group instances: a groups whose role is to provide access to credit, another whose role is to attribute water and third which manages the pumping station.
}

terviewed the whose result is satisfactory: either the one who obtained best result for the criterion or the one whose set of rules is the least different from its own. Once each agent has updated its set of rules, he implements them the following season.

Viability is evaluated with the number of cropping seasons a simulation lasts and with the rate of cultivated plots for each season. Simulations are based on scenarios describing patterns of rules for agents in the model, groups and farmers, and a few parameters concerning their environment.

We have thus set up a multi-agent system in which two different levels of organization are implemented. These two levels interact by communicating and by acting within the same space. They co-evolve through repeated evaluations which enable them to learn and to adapt to what the others are doing on the basis of their own satisfaction criteria. This multi-agent system is used to test the effect of the different simulated coordination mechanisms on the viability of irrigated systems.

A first series of simulations, which consisted in random scenarios, showed that no rule, neither collective nor individual, seemed to explain by its own of the system's viability. In a second step, we described a scenario as a set of three "chromosomes": one gathers parameters relatives to collective rules, a second one gathers parameters relatives to individual behaviors and the third one gathers parameters relatives to the environment. In some cases, swapping a chromosome from a viable scenario to another one and vice-versa leads to two non viable scenarios[2]. This shows that there is neither good or bad set of collective rules nor good or bad sets of individual behaviors. These simulations lead us to raise the hypothesis that viability of irrigated systems may depend on the coherence between sets of rules from collective and individual levels.

\section{Towards a simulation tool: CORMAS}

We concluded the first part of this article by showing that one method to enrich the analyse of acts of individuals in society was to take into account the point of view of the actors and the explanations it gives of its social environment. At the same time we know that it is possible to identify several levels of agregation that structure the group. In both models we described, one size of this complexity is taken into account. In the one that concerns the potlatch, different representations of the same emergent object are built during the simulations, these perceptions being potentially contradictory. In the one concerning irrigated systems, the relations between the individual agents and the agentified group are real interactions, each one influencing the other: the group with its rules, the individual by changing the level of satisfaction. However, both approaches are hard to synthetise. 
In problems of common property management, we most study the viability of a system in terms of a balance between the autonomy of individuals and control by a collective level. Both of these levels interact with a dynamical environment. As we saw, two approaches can be used to identify and model the collective level: either the notion of collective is considered as the viewpoint of an observer outside the system, the agents being unaware of it; or it is created and agentified by the modeller since the beginning of the simulation. That is why we built a tool, based on MAS to coordinate at the same time different levels of agregation, some of them being emergent, and different points of view (and to compare individuals' perception of the collective to what it actually is).

Cormas tool was built using VisualWorks. It uses and proposes Smalltalk as a development language. Cormas is used to develop multi-agent simulation models. Different types of programs are proposed to the modeller. The first type of program concerns the agents and the interactions between agents are defined in space or through communication. The environment is represented by a spatial grid. The dynamics of the environment is simulated like a cellular automata. The principles of the tool are similar to the Sugarscape principles [11] Different types of agents are defined : situated agents, communicating agents, and group agents. The situated agents possesses a spatial reference and has as a perception range. A communicating agent possesses a mailbox. The group agent is defined as a communicating agent which is composed of other agents or cells of the environment.

The second set of programs concerns overall control of the dynamics while the third set seeks to define an observation of the simulated system. Three interfaces are proposed: first scientific graphs, second a grid to visualize all the cells and situated agents. The third layer is a link observer which is used to observe the communicating agents and communication graphs which structure the networks [34]. Figure 1 presents an example of this tool. Two groups of communicating agents are observed.

Thus the Cormas environment proposes two tools at the same time. It helps the observer to identify and describe the sets of communicating agents which can be considered as groups and their dynamics. Cormas also offers the possibility to implement group agents.

Hence Cormas enables the user to interact with the simulation going: once the structure is analyzed in terms of links and dynamics, it is then possible to define the community as an agent of the multi-agent system. Then are its operations and rules described as well as the way several organization levels coordination. Taking into account some results observed, we have already implemented a range examples which can be used by any modeller: it is possible to choose between different instances of Group, and of relations be-

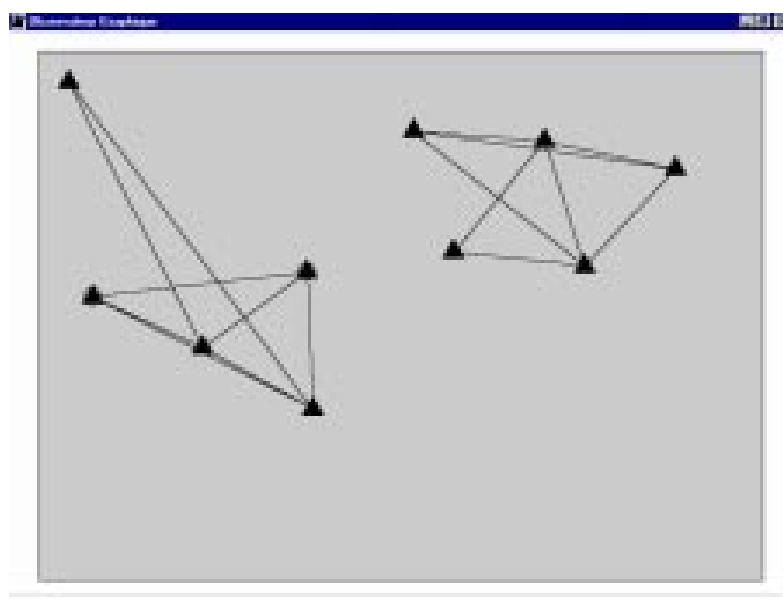

Figure 1. The triangles represent the agents. A line is displayed between interacting agents. After some time steps one can observe on the interface that the set of agents has been structured in two groups

tween these groups and the individuals that constitute them.

Considering these characteristics, Cormas seems to be a simulation environment adapted our way to consider the question of system viability. The coadaptation of the different levels and the quality of the representations of one level with respect to another are really taken into account and can be used to treat different subject.

\section{References}

[1] O. Barreteau, F. Bousquet, and J. Weber. Modes de gestion et viabilité des périmètres irrigués: questions de représentation. In F. Blasco, editor, Tendances nouvelles en modélisation pour l'environnement, pages 153-159, Paris, 1997. Elsevier.

[2] O. Barreteau and J. Weber. Cohérence entre règles collectives et comportements individuels dans des systèmes irrigués. In Journées de L'association Française de Sciences Économiques - Économie de L'environnement et Des Ressources Naturelles, 1998.

[3] F. Boas. Kwakiutl Ethnography. The Univerity of Chicago Press, 1966.

[4] L. Boltanski and L. Thevenot. De la Justification, Les Économies de la Grandeur. Gallimard, 1991.

[5] F. Bousquet. Usages des ressources renouvelables et modélisation des représentations: une approche par les systèmes multi-agents. In F. Blasco, editor, Tendances nouvelles en modélisation pour l'environnement, pages 187193, Paris, 1997. Elsevier.

[6] A. Caillé. Philosophie et Anthropologie, chapter Sujet individuel et sujet collectif. Editions du centre de Pompidou, 1992. 
[7] A. Caille. Don, Intérêt et Désintéressement. Bourdieu, Mauss, Platon et Quelques Autres. La Découverte/ M.A.U.S.S, 1994.

[8] A. Coulon. L'ethnométhodologie. Puf, 1987.

[9] J. Doran and M. Palmer. The EOS project : Integrating two models of paleolithic social change. In N. G. . R. Conte, editor, Artificial Societies. UCL Press, 1993.

[10] A. Drogoul. La mémoire collective dans les sma réactifs : L'exemple de manta. In Mémoire Collective, Dialogue Entre Les Sma Artificiels et Les Sciences Humaines et Biologiques. Centrede recherche de Royallieu, Compiègne, 1994.

[11] J. Epstein and R. Axtell. Growing Artificial Societies. Social Science from the Bottom Up. Brookins Institution Press/ The MIT Press, 1996.

[12] O. Favereau. Règle, organisation et apprentissage collectif : Un paradigme non-standard pour trois théories hétérodoxes. La revue économique, 40:113-137, 1989.

[13] J. Ferber. La kénétique : Des systèmes multi-agents à une science de l'interaction. Revue internationale de systémique, 8:13-27, 1994.

[14] J. Ferber. Les Systèmes Multi-Agents. Vers une intelligence collective. InterEditions, Paris, 1995.

[15] A. Giddens. La Constitution de la Société. PUF, 1987.

[16] N. Glance and B. Huberman. Organizational fluidity and sustainable cooperation. Lecture Notes in Artificial Intelligence, 957:89-103, 1995.

[17] M. Godelier. L'idéel et Le Matériel. Fayard, 1986.

[18] M. Godelier. L'énigme Du Don. Fayard, 1996.

[19] G. Granger. L'explication dans les sciences sociales. nouvelle bibliothèque scientifique flammarion, 1973.

[20] J. Habermas. The Theory of Communicative Action, Vol 1: Reason and the Rationalization of Society. Campbridge Polity Press, 1986.

[21] V. Havelange. Sciences cognitives et tradition sociologique. Revue internationale de systémique, 8:79-89, 1994.

[22] V. Havelange. Cognition et théorie sociologique de l'action. In C. Lenay, editor, Mémoires, Inscriptions, Actions Individuelles et Collectives. UTC, 1996.

[23] E. Hutchins. Culture and Inference. A Trobriand Case Study. Harvard University Press, 1980.

[24] A. Ito. How do autonomous agents solve social dilemmas? Lecture Notes in Artificial Intelligence, 1209:177188, 1997.

[25] B. Lahire. Précisions sur la manière sociologique de traiter du sens : Quelques remarques concernant l'ethnométhodologie. Langage et société, 59:73-89, 1992.

[26] D. Layder. Understanding Social Theory. SAGE Publications, 1994.

[27] C. Lenay. JFIADSMA 96, chapter Coopération et intentionnalité, pages 265-271. Hermès, 1996.

[28] C. Lévi-Strauss. Sociologie et Anthropologie, chapter Introduction. PUF, 1968.

[29] P. Livet and L. Thévenot. Les catégories de l'action collective. Revue économique, 40:139-167, 1989.

[30] M. Mauss. Sociologie et Anthropologie. PUF, 1968.

[31] M. Minsky. La Société de L'esprit. Interéditions, 1988.

[32] J. Muller. The Design of Intelligent Agents. Springer, 1996.

[33] E. Ostrom. Governing the Commons. Cambridge University Press, 1990.
[34] H. Proton, F. Bousquet, and P. Reitz. Un outil pour observer l'organisation d'une société d'agents. le cas d'une société d'agents chasseurs-agriculteurs. In J. Quinqueton, M. Thomas, and B. Trousse, editors, Actes des 5èmes journées francophones sur l'IAD et les SMA, pages 159172, Paris, 1997. Hermès.

[35] A. Rao, M. Georgeff, and E. Sonnenberg. Decentralized AI, chapter Social plans: a preliminary report. Elsevier, 1992.

[36] J. Tabary. Représnetation mentale, biologie et constructivisme radical. In Les Modéles de Représenation : Quelles Alternatives?, Neuchatel, 1997. Colloque interdisciplinaire.

[37] F. Varela, E. Thompson, and E. Rosch. L'inscription Corporelle de L'esprit, Sciences Cognitives et Expérience Humaine. Seuil, 1993.

[38] P. Watzlawick, J. Beavin, and D. Jackson. Une Logique de la Communication. Seuil, 1972.

[39] A. Weill-Fassina, P. Rabardel, and D. Dubois. Représentations Pour L'action. Octares editions, 1993. 